
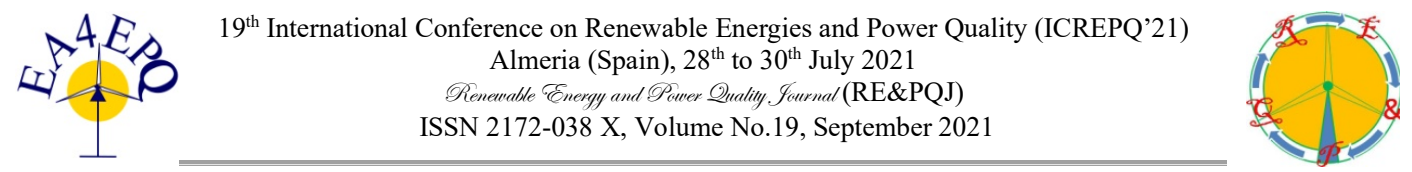

\title{
Continuous Cross-Period Single Phase Shift Control for Dual Active Bridge Converters
}

\author{
Szabolcs Veréb, András Futó, Zoltán Sütő, Attila Balogh and István Varjasi \\ Power Electronics Research Group \\ Department of Automation and Applied Informatics \\ Budapest University of Technology and Economics \\ Magyar tudósok krt. 2. (Bldg. Q.), Budapest H-1117, Hungary \\ Phone number: +36 (1) 463-1552, e-mail: szabolcs.vereb@edu.bme.hu
}

\begin{abstract}
The dynamic load transient response of dual active bridge converters is mainly dependent on the switching frequency, leakage inductance and capacitor bank size. Traditional singe phase shift control mechanism can react slowly to a rapid load change, especially in applications where the switching frequency is low. Several control algorithms were published throughout the years, however, few of them are focusing on transient behavior. In this paper a novel control technique is presented which aims for dynamic performance. The mathematical basis of operation is presented and an appropriate control scheme is proposed, which is tested in a real application. The study reveled that the continuous cross-period single phase shift control technique has better load transient response than the traditional singe phase shift method.
\end{abstract}

Key words. DAB converter, $400 \mathrm{~Hz}$ transformer, isolated converter, power conversion

\section{Introduction}

Nowadays, vehicle electrification is still gaining more popularity, most car manufacturer companies are developing their own solution to have a more environment friendly alternative to internal combustion engine powered automobiles. At the Budapest University of Technology and Economics the Modular Hybrid Drive System (MHDS) Laboratory was built to serve the testing needs of electric and hybrid car development. This laboratory includes a $360 \mathrm{~kW}$ nominal power dual-activebridge (DAB) converter (Fig. 2), which is the main motivation to this paper.

The DAB topology, as an efficient, isolated, bidirectional DC-DC converter, was proposed [1] and patented [2] in 1991. As the name suggests, the topology consists of two full-bridges and a transformer between them, the main circuit diagram is shown on Fig. 1. The transformer leakage inductance is a key part in the operation of the converter [3].

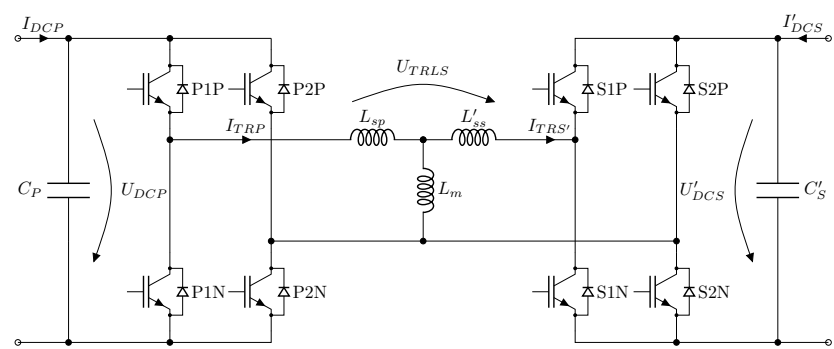

Fig. 1. Power circuit schematic diagram of the DAB converter

In the last few decades multiple different control methods were developed for the DAB topology. The Single Phase Shift control is the simplest and the most commonly used [1] [3], which could be improved to have wider ZVS region and reduce the circulation power issue [4]. More advanced control techniques are the Double Phase Shift (DPS) [5] and Triple Phase Shift (TPS) [6] control, however these have more degrees of freedom in control parameters, which makes them complicated to implement in a real application.

A high power DC test equipment usually requires galvanic isolation. The DAB topology could be an appropriate choice. The latest publications are focusing on enchaining efficiency [7] [8] [9] and increasing the frequency to reduce physical size [10], however the load transient response of the system is a key property in such applications.

A good transient response can be characterized by fast, voltage overshoot free settling and overcurrent free behavior, which can be achieved by using a transformer with very little leakage inductance, high switching frequency and a large capacitor bank. The main issue is that creating high frequency transformer cores above $100 \mathrm{~kW}$ is expensive and hard to manufacture. In the MHDS laboratory a $400 \mathrm{~Hz}$ steel core transformer 


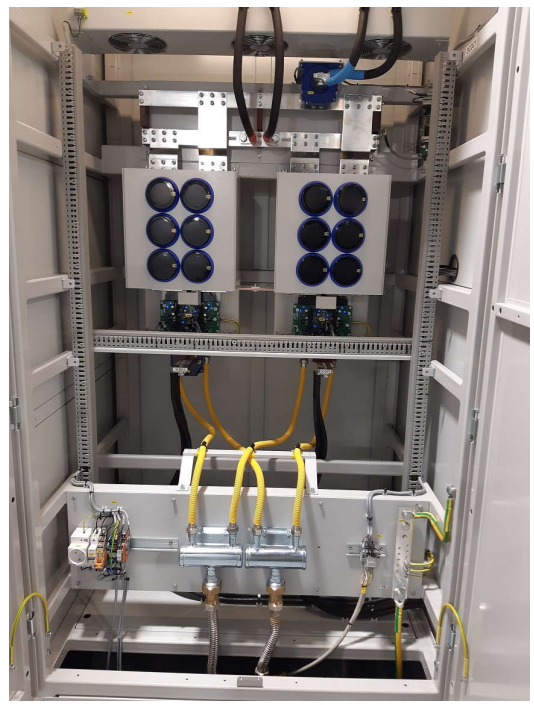

(a) primary side bridge

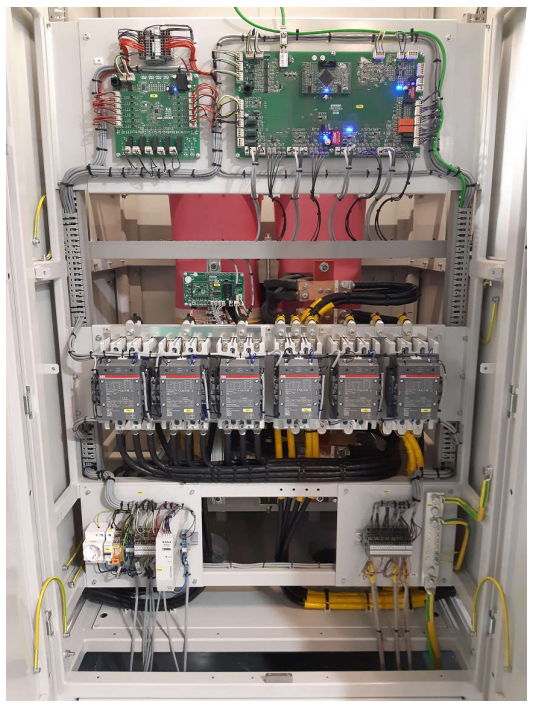

(b) transformer, control and contactors

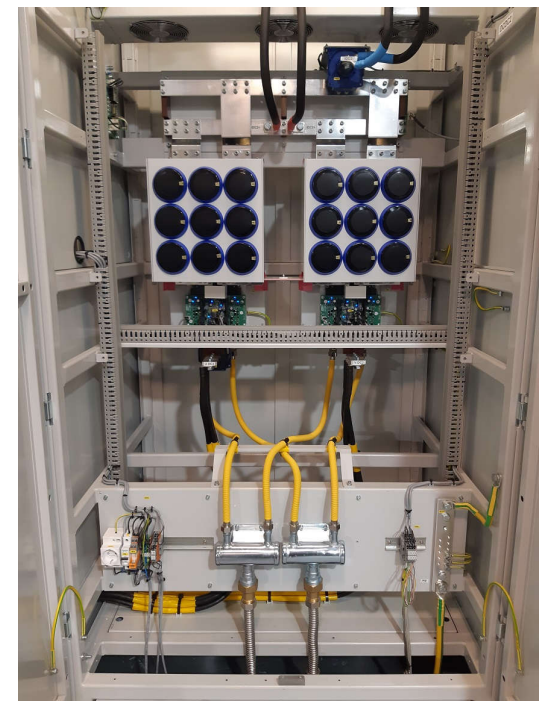

(c) secondary side bridge

Fig. 2. The $360 k W$ DAB converter in the MHDS laboratory used for the experiments

was chosen as a cost-effective solution. This type of transformer is widely available as they are used in the aviation industry. Lowering the switching frequency would result with enormously large capacitor bank if excellent dynamic behavior wanted to be achieved with classic control methods.

Instead of this, a novel control technique, called Cross-Period Single Phase Shift (CP-SPS), was proposed by the authors for such low frequency applications [11] together with a switch delay and deadtime compensation method [12]. This control was depending on load current forward feed, which may cause issues when the load has high input capacitance and the inductance is high between the converter and the load (e.g. an inverter connected with long leads). In this paper an improved control technique is presented, which is not using the load current forward feed in the control loop, allowing further cost reduction and the usage of inductive-capacitive loads.

In Section 2 the proposed control technique and its main equations are presented. An applicable control scheme is shown in Section 3 together with a discrete PI controller implementation and tuning in Section 4, which is tested in the MHDS laboratory as described in Section 5.

\section{Proposed control technique}

The basic idea of the Continuous Cross-Period Single Phase Shift control (CCP-SPS) is to use the conventional SPS switching technique supplemented with additional four in-period switching actions in a way, that the transformer magnetizing current fundamental frequency is not increased, but the control loop could be running three times faster resulting with better dynamic behavior.

The waveforms of the proposed control are shown on Fig. 3 demonstrating the possible switching actions.
The fundamental time period $\left(T_{S P S}\right)$ is divided into six $T_{C C P}$ long durations (or phases), marked with PH1PH6. Similarly to SPS control, the transformer current can be changed in PH1 and PH4 with a phase shift between the primary and secondary side transformer voltage, which can be expressed as a duty cycle:

$$
d_{S P S}=\frac{\Delta I_{S P S}}{T_{C C P}} \frac{L_{s p}+L_{s s}^{\prime}}{U_{D C P}+U_{D C S}^{\prime}}=K_{I} \Delta I_{S P S}
$$

With only using $d_{S P S}$ to control the transformer current, the system can only react to load transients in every $T_{S P S} / 2$ seconds. The switching actions in $\mathrm{PH} 2$, PH3, PH5 and PH6 introduced by CCP-SPS control reduces system reaction deadtime to $T_{C C P}=T_{S P S} / 6$ in worst case. In these phases the transformer primary and secondary side is shorted for a fixed $d_{\max }$ time, even if no current change is necessary. If one of the active half bridge legs are switched with $d_{C C P}$ delay compared to the other one, the transformer current can be changed as the voltage forced to the leakage inductance is not zero. The transformer current can be increased or decreased independently of its direction as shown in the following equations:

$$
\begin{aligned}
& d_{C C P}^{2,3,+}=d_{C C P}^{5,6,-}=\frac{\Delta I_{C C P}}{T_{C}} \frac{L_{s p}+L_{s s}^{\prime}}{U_{D C P}}=K_{I} \Delta I_{C C P} \\
& d_{C C P}^{2,3,-}=d_{C C P}^{5,6,+}=\frac{\Delta I_{C C P}}{T_{C}} \frac{L_{s p}+L_{s s}^{\prime}}{U_{D C S}^{\prime}}=K_{I} \Delta I_{C C P}
\end{aligned}
$$

$d_{\max }$ is the upper limit for the delay, which defines the achievable current level change.

The reason for using a fixed $d_{\max }$ long transformer shorting time is to allow very fine control over the voltage-time product on the leakage inductance. In theory the same effect would be achievable by only switching one half bridge leg for a short period of time (as it is done in CP-SPS control [11]), however in real applications, where switch delay is not negligible, there 
is a lower limit for the applicable voltage-time product, hence for the current change. During the transformer shorting time periods the magnetizing inductance voltage is zero, thus the magnetizing current will have a flat plateau. If the transformer leakage inductance is low, the required $d_{\max }$ time will have a low value, which makes this effect negligible.

\section{Control scheme}

An appropriate control loop is shown on Fig. 4. As $d_{S P S} \ll 1, I_{D C P}$ can be estimated by the transformer half-period average current (see $I_{A V G}$ on Fig. 3). This is regulated with a model based controller ( $I$ control), where $K_{I}$ is dependent on the phase the controller is running at and the sign of error, the calculations are based on equations (1)-(3). If the transformer parameters and the voltages are well known, the transformer current will reach the average current reference after the switching actions. The average current reference is provided by a voltage PI controller ( $U$ control).

The $I_{L m}$ controller is responsible to prevent transformer core saturation. This is achieved by estimating the transformer magnetizing current DC component $\left(I_{L m D C}\right)$ and a PI regulator tries to keep this measured value at zero.

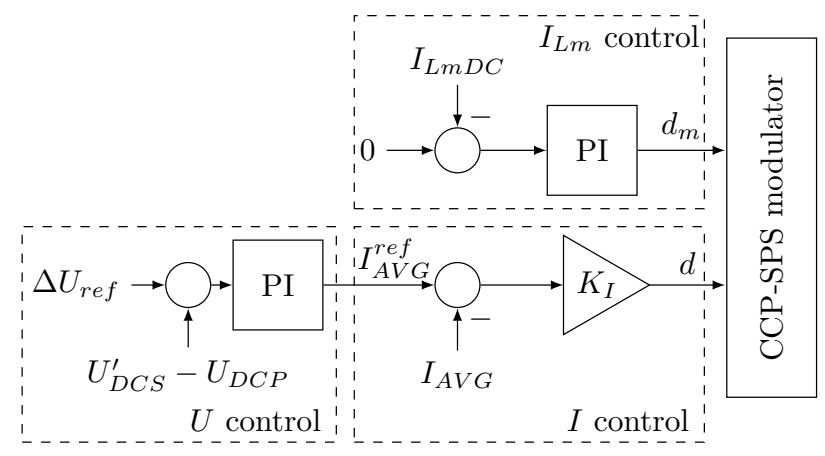

Fig. 4. Control diagram for the Continuous CrossPeriod Single Phase Shift algorithm

The calculated duty cycles $\left(d\right.$ and $\left.d_{m}\right)$ are fed into a modulator block, which generates the required switching signals as shown in Tab. I.

\section{Digital control implementation}

The proposed control loop was implemented on a Texas Instruments TMS320F28075 DSP. All the ana$\log$ measurements are triggered at the start of each control phase (PHx), in other words, when the PWM

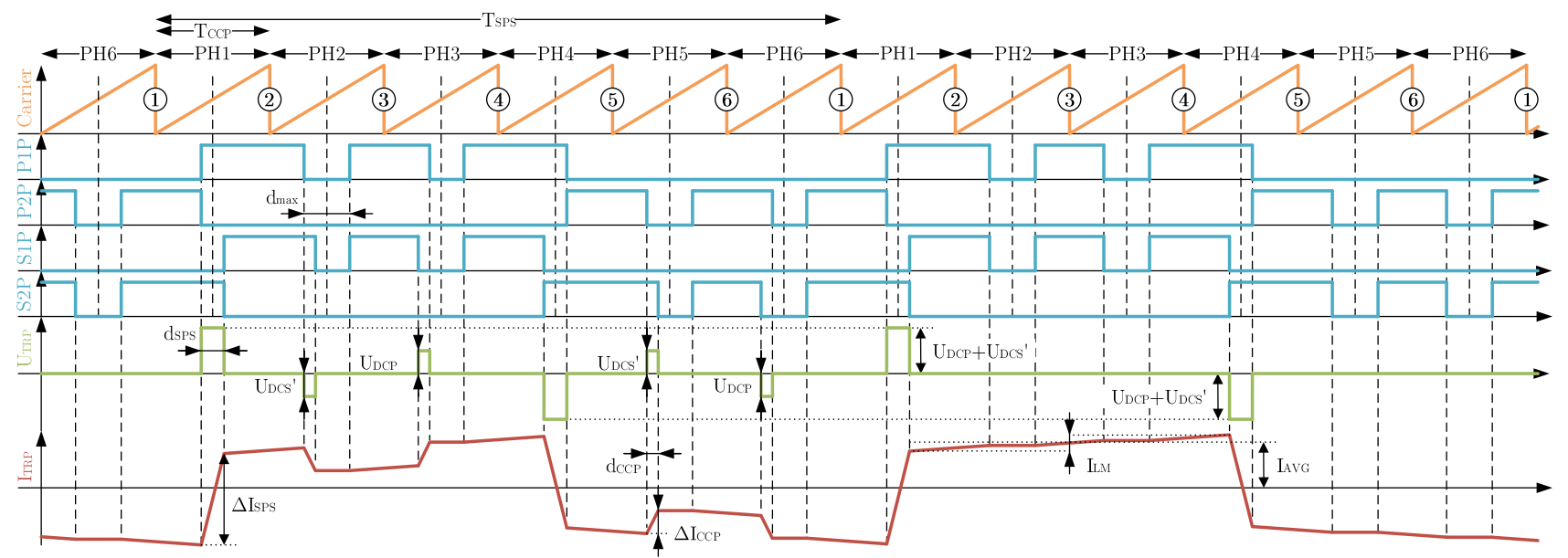

Fig. 3. CCP-SPS control resulting waveform illustrating possible in-period transformer current modifications. Only top switch gate signals are shown as $P 1 N=\overline{P 1 P}, P 2 N=\overline{P 2 P}, S 1 N=\overline{S 1 P}, S 2 N=\overline{S 2 P}$. For better visibility $d_{S P S}, d_{C C P}$ and $d_{\max }$ are illustrated with longer time periods as it would be in a low leakage application.

Table I - CCP-SPS modulator switching table with compare values suitable for unit sawtooth carrier signal.

\begin{tabular}{|c|c|c|c|c|c|c|}
\hline & \multirow[t]{2}{*}{ PH1 } & \multicolumn{2}{|c|}{$\mathrm{PH} 2$ and $\mathrm{PH} 3$} & \multicolumn{2}{|c|}{ PH5 and PH6 } & \multirow[t]{2}{*}{$\mathrm{PH} 4$} \\
\hline & & $I_{e r r}>0$ & $I_{e r r} \leq 0$ & $I_{e r r}>0$ & $I_{e r r} \leq 0$ & \\
\hline $\mathrm{P} 1$ to $U_{D C P}$ & $0.5-d_{m}-\frac{d}{2}$ & $0.5+\frac{d_{\max }}{2}$ & $0.5+\frac{d_{\max }}{2}$ & $\mathrm{x}$ & $\mathrm{x}$ & $\mathrm{x}$ \\
\hline $\mathrm{P} 1$ to 0 & $\mathrm{x}$ & $0.5-\frac{d_{\max }}{2}+d$ & $0.5-\frac{d_{\max }^{2}}{2}$ & $\mathrm{x}$ & $\mathrm{x}$ & $0.5+d_{m}-\frac{d}{2}$ \\
\hline P2 to $U_{D C P}$ & $\mathrm{x}$ & $\mathrm{x}^{2}$ & $\mathrm{x}^{2}$ & $0.5+\frac{d_{\max }}{2}$ & $0.5+\frac{d_{\max }}{2}$ & $0.5+d_{m}-\frac{d}{2}$ \\
\hline $\mathrm{P} 2$ to 0 & $0.5-d_{m}-\frac{d}{2}$ & $\mathrm{x}$ & $\mathrm{x}$ & $0.5-\frac{d_{\max }}{2}+d$ & $0.5+\frac{d_{\max }^{2}}{2}$ & $\mathrm{x}^{2}$ \\
\hline S1 to $U_{D C S}$ & $0.5-d_{m}+\frac{d}{2}$ & $0.5+\frac{d_{\max }}{2}$ & $0.5+\frac{d_{\max }}{2}$ & $\mathrm{x}$ & $\mathrm{x}$ & $\mathrm{x}$ \\
\hline S1 to 0 & $\mathrm{x}$ & $0.5-\frac{d_{\max }^{2}}{2}$ & $0.5-\frac{d_{\max }}{2}+d$ & $\mathrm{x}$ & $\mathrm{x}$ & $0.5+d_{m}+\frac{d}{2}$ \\
\hline $\mathrm{S} 2$ to $U_{D C S}$ & $\mathrm{x}$ & $\mathrm{x}^{2}$ & $\mathrm{x}$ & $0.5+\frac{d_{\max }}{2}$ & $0.5+\frac{d_{\max }}{2}$ & $0.5+d_{m}+\frac{d}{2}$ \\
\hline $\mathrm{S} 2$ to 0 & $0.5-d_{m}+\frac{d}{2}$ & $\mathrm{x}$ & $\mathrm{x}$ & $0.5-\frac{d_{\max }^{2}}{2}$ & $0.5+\frac{d_{\max }}{2}+d$ & $\mathrm{x}^{2}$ \\
\hline
\end{tabular}




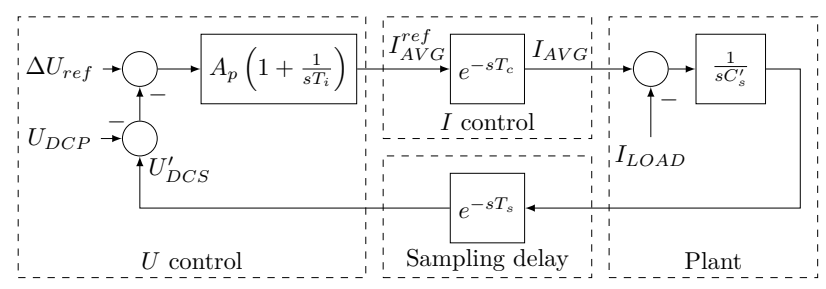

Fig. 5. Control tuning diagram for the Cross-Period Single Phase Shift algorithm

carrier signal is reset to zero (see the numbered circles on Fig. 3). The control logic is running after the completion of the ADC conversions and the new switching actions are actuated in the same phase.

In the following pages the SPS and CCP-SPS control loop settling time is compared, the SPS control is implemented by simply disabling the calculation and switching in $\mathrm{PH} 2, \mathrm{PH} 3, \mathrm{PH} 5$ and $\mathrm{PH} 6$ and using different PI controller settings.

The voltage controller is tuned based on the closed loop control diagram (Fig. 5). The parameters are selected to achieve the fastest disturbance response without overshoot. The model based current control loop is substituted with a $T_{c}$ delay, which is caused by the time difference between sampling the voltage, running the control logic and actuating the switching. $T_{c}$ is equal to the half of one phase duration for both SPS and CCP-SPS. Because of the system sampled nature, the measurement is modeled with a $T_{s}$ delay, which is the average time difference of a change in the plant and the next sampling point after it. The calculated delays are shown in equations (4)-(6). The plant contains the load current as a disturbance and an integrator which represents the secondary side capacitor.

$$
\begin{aligned}
T_{c}^{S P S}=T_{c}^{C C P} & =\frac{1}{2} T_{C C P}=\frac{1}{12} T_{S P S} \\
T_{s}^{S P S} & =\frac{3}{2} T_{C C P}=\frac{1}{4} T_{S P S} \\
T_{s}^{C C P} & =\frac{1}{2} T_{C C P}=\frac{1}{12} T_{S P S}
\end{aligned}
$$

To achieve overshoot free response a phase margin of $60 \mathrm{deg}$ was selected and the remaining phase is distributed between the loop delay and the PI controller in a $2 / 3$ and $1 / 3$ ratio. The open loop transfer function is given as (7), from which the amplitude and phase equations is derived shown in (8) and (9).

$$
\begin{aligned}
W_{o}(s) & =A_{p}\left(1+\frac{1}{s T_{i}}\right) e^{-s\left(T_{c}+T_{s}\right)} \frac{1}{s C_{s}^{\prime}} \\
\left|W_{o}\left(\omega_{c}\right)\right| & =A_{p} \sqrt{1+\left(\frac{1}{\omega_{c} T_{i}}\right)^{2}} \frac{1}{\omega_{c} C}=1 \\
\angle W_{o}\left(\omega_{c}\right) & =-\operatorname{atan}\left(\frac{1}{\omega_{c} T_{i}}\right)-\omega_{c}\left(T_{c}+T_{s}\right)-\frac{\pi}{2}= \\
& =-\pi+\varphi_{m}
\end{aligned}
$$

Table II - PI controller tuning parameters

\begin{tabular}{ccrrcc}
\hline & $\omega_{c}$ & \multicolumn{1}{c}{$T_{i}$} & \multicolumn{1}{c}{$A_{p}$} & $P$ & $I$ \\
\hline SPS & $418.9 \mathrm{rad} / \mathrm{s}$ & $13.5 \mathrm{~ms}$ & $5.7 A / V$ & 5.434 & 0.263 \\
CCP-SPS & $837.8 \mathrm{rad} / \mathrm{s}$ & $6.8 \mathrm{~ms}$ & $11.4 A / V$ & 11.04 & 0.351 \\
\hline
\end{tabular}

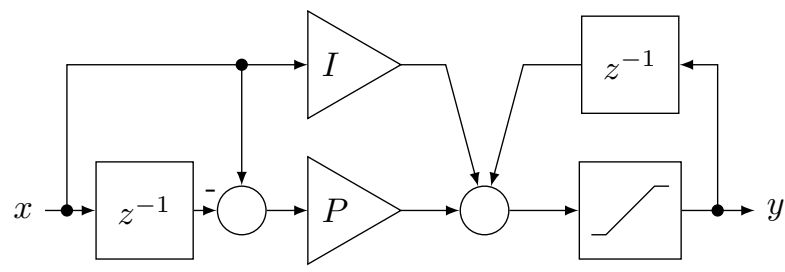

Fig. 6. PI controller implementation in the DSP firmware

The cutoff angular frequency $\left(\omega_{c}\right)$ can be expressed from (9) by distributing $2 / 3$ of the remaining phase to the loop delay with $60^{\circ}$ phase margin, as shown in (10).

$$
\omega_{c}\left(T_{c}+T_{s}\right)=\frac{2}{3}\left(\frac{\pi}{2}-\frac{\pi}{6}\right) \Rightarrow \omega_{c}=\frac{\pi}{9} \frac{1}{\left(T_{c}+T_{s}\right)}
$$

The rest of the remaining phase is distributed in $1 / 3$ ratio to the $\mathrm{PI}$ controller, which gives the integration time $\left(T_{i}\right)$ as shown in (11).

$$
\operatorname{atan}\left(\frac{1}{\omega_{c} T_{i}}\right)=\frac{1}{3}\left(\frac{\pi}{2}-\frac{\pi}{6}\right) \Rightarrow T_{i}=\frac{1}{\omega_{c} \tan \frac{\pi}{18}}
$$

The PI controller gain $\left(A_{p}\right)$ can be derived from (8) using $w_{c}$ and $T_{i}$ as shown in (12).

$$
A_{p}=\frac{\omega_{c} C_{s}^{\prime}}{\sqrt{1+\left(\frac{1}{\omega_{c} T_{i}}\right)^{2}}} \approx \omega_{c} C_{s}^{\prime}
$$

From the equations it can be seen that for the CCPSPS control a higher cutoff angular frequency can be used to achieve the same phase margin, which makes the control loop faster than with SPS. The calculated and used values for $400 \mathrm{~Hz}$ switching frequency $\left(T_{S P S}=2.5 \mathrm{~ms}\right)$ can be found in Tab. II.

In the DSP, the digital PI controller is implemented as shown in Fig. 6, the Forward-Euler Z-domain transfer function can be written as (13).

$$
\frac{y(z)}{x(z)}=\frac{(P+I)(z-1)+I}{z-1}
$$

Comparing this to the same Z-domain representation of an S-domain PI controller, shown in (14), the $P$ and $I$ parameter equations can be derived as (15) and (16). 
Table III - Transformer parameters

\begin{tabular}{cccc}
\hline Turns ratio & $L_{s p}$ & $L_{s s}^{\prime}$ & $L_{m}$ \\
\hline 1.5 and 0.75 & $17.0 \mu H$ & $17.0 \mu H$ & $5.0 m H$ \\
1.2 and 0.6 & $25.3 \mu H$ & $25.3 \mu H$ & $7.9 m H$ \\
1.0 and 0.5 & $28.2 \mu H$ & $28.2 \mu H$ & $11.1 m H$ \\
\hline
\end{tabular}

$$
\begin{aligned}
W_{P I}(z) & =\frac{A_{p}(z-1)+T_{s} A_{p} / T_{i}}{z-1} \\
P & =A_{p}-T_{s} \frac{A_{p}}{T_{i}} \\
I & =T_{s} \frac{A_{p}}{T_{i}}
\end{aligned}
$$

Due to the sampling time and continuous time control parameters' differences, the $P$ and $I$ values are not the same, the used parameters can be found in Tab. II.

\section{Test in real application}

The SPS and the proposed CCP-SPS controls were compared in the MHDS laboratory on a $360 \mathrm{~kW}$ DAB converter (Fig. 2). The transformer has multiple windings which can be selected by multiple contactors prior to starting the equipment. The configurable turns-ratios and the resulting transformer inductances are summarized in Tab. III. The DC capacitor banks are build up from multiple capacitors in series and parallel connection to reach the required voltage and capacitance. The effective capacitance is $20.4 \mathrm{mF}$ on the primary $\left(C_{P}\right)$ and $13.6 \mathrm{mF}$ on the secondary side $\left(C_{S}\right)$. The bridges are built up from Mitsubishi CM1000DUC-34SA modules (1700V/1000A), which are controlled with a TMS320F28075 DSP.

Other converters of the laboratory was leveraged for the tests. From the $3 \times 400 V A C$ grid an active rectifier was providing $675 \mathrm{VDC}$ voltage onto the $\mathrm{DAB}$ converter primary side. The DAB converter transformer was set to $n=1.2$, creating $810 \mathrm{VDC}$ nominal voltage on its secondary side. A bidirectional, nonisolated DC/DC converter was used to create a power flow from the DAB converter secondary side to its primary side. This way the power was circulating in the laboratory, the active rectifier only had to provide the dissipated energy. The DC/DC converter was able to ramp up/down the current in $1 \mathrm{~ms}$.

Three types of tests were conducted to analyze the dynamic performance of the control loop:

- load transient from $0 A$ to $250 A$,

- load dump from $250 A$ to $0 A$ and

- $10 H z$ AC superimposed to DC current $(250 A+50 A \sin (2 \pi 10 t))$.

During the tests, the primary and secondary DC voltage and transformer current was measured with differential voltage measurement probes and Tektronix
Table IV - $\Delta U_{D C S}^{\prime}$ peak-to-peak comparison.

\begin{tabular}{rrrr}
\hline Test case & $\Delta U_{D C S^{\prime}}^{S P S}$ & \multicolumn{2}{c}{$\Delta U_{D C S^{\prime}}^{C C P}$} \\
\hline $0 A \rightarrow 250 A$ & $23.0 \mathrm{~V}$ & $17.4 \mathrm{~V}$ & $-24.3 \%$ \\
$250 \mathrm{~A} \rightarrow 0 \mathrm{~A}$ & $20.0 \mathrm{~V}$ & $16.6 \mathrm{~V}$ & $-17.0 \%$ \\
$\mathrm{AC}+\mathrm{DC}$ & $9.0 \mathrm{~V}$ & $6.2 \mathrm{~V}$ & $-31.1 \%$ \\
\hline
\end{tabular}

A6304XL current sensors connected to a 4 channel oscilloscope. The results are shown on Fig. 7 and Fig. 8, where the measured values are plotted reduced to the primary side.

Due to other system requirements, $\Delta U_{\text {ref }}$ was changing depending on the load current, which results with a different stationary secondary voltage level before and after the transients. The steady state current waveforms of CCP-SPS can be observed in Fig. 7d zoomed area, while the transient waveforms are illustreted in Fig. 7b. The visible current level imperfections after a switching action are caused by switching deadtime.

It can be clearly seen on Fig. 7 that the secondary voltage transient disappears faster with the CCP-SPS control in both current change directions, the final value is reached around twice as fast. The amplitude of the voltage transient is smaller as well. Another benefit of CCP-SPS is the lower peak transformer current, thus preventing overcurrent events in case of a higher load.

The superimposed test results are shown on Fig. 8, the voltage plots are including the secondary side voltage DFT for comparison. With CCP-SPS the low frequency components are attenuated compared to SPS, proving the ability to compensate errors with higher bandwidth.

The transient peak-to-peak reduced secondary side voltage is extracted from the measurement data and summarized in Tab. IV. The CCP-SPS control results with few $10 \%$ lower peak-to-peak voltage swing compared to the SPS control depending on the load type and direction of power flow.

\section{Conclusion}

In this paper a novel control technique was proposed to be used with DAB converters to improve load transient response properties, especially for applications where the transformer has low leakage inductance and low allowed switching frequency. An appropriate control scheme was presented, which maintains voltage balance and includes an anti transformer saturation controller.

The digital voltage PI controller implementation was presented together with a parameter tuning method to achieve the fastest overshoot free transient characteristics.

The proposed algorithm and control loop was tested in a $360 \mathrm{~kW}$ application proving that the CCP-SPS control has better load transient response compared to SPS control. 

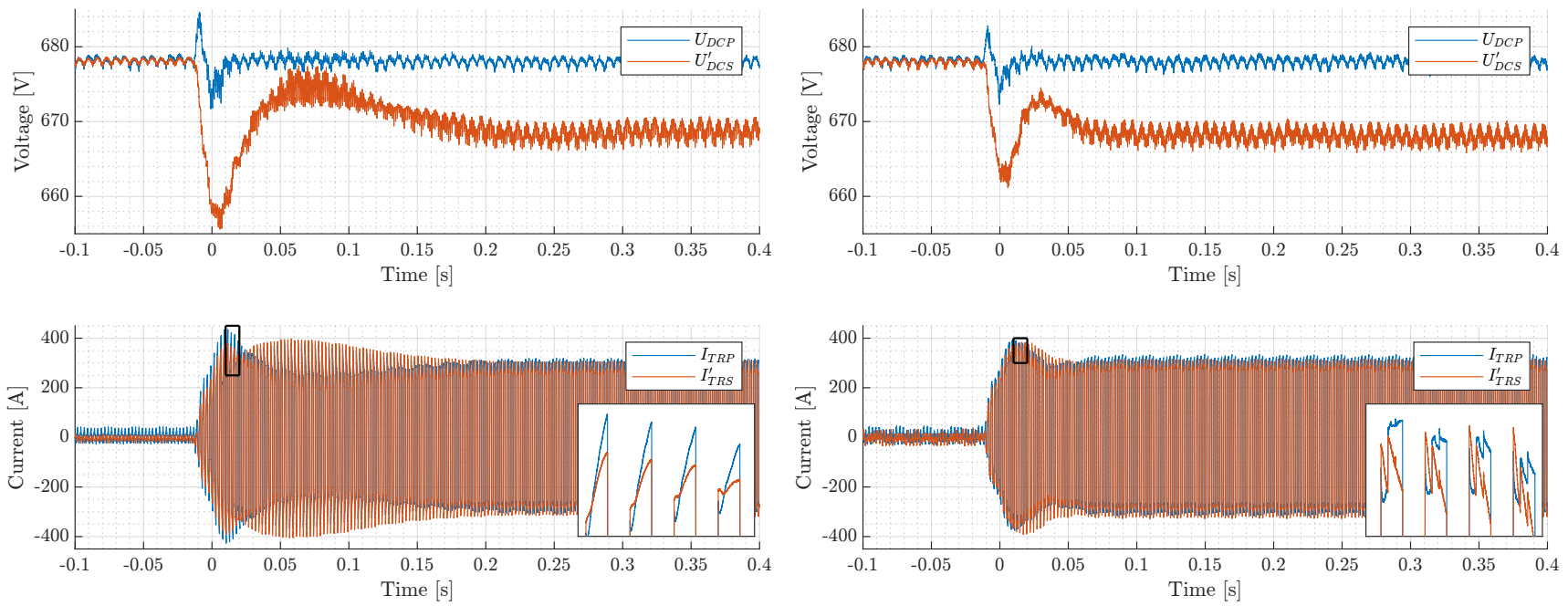

(a) SPS, $0 A \rightarrow 250 A$

(b) CCP-SPS, $0 A \rightarrow 250 A$
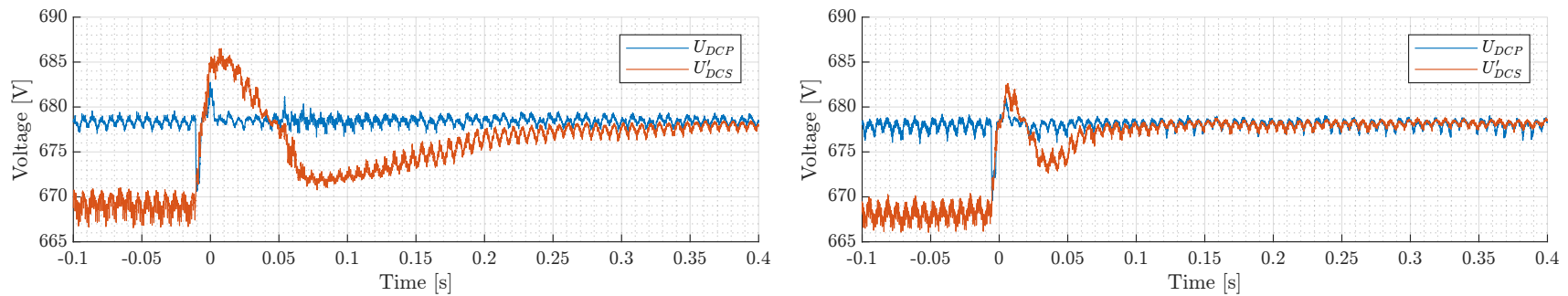

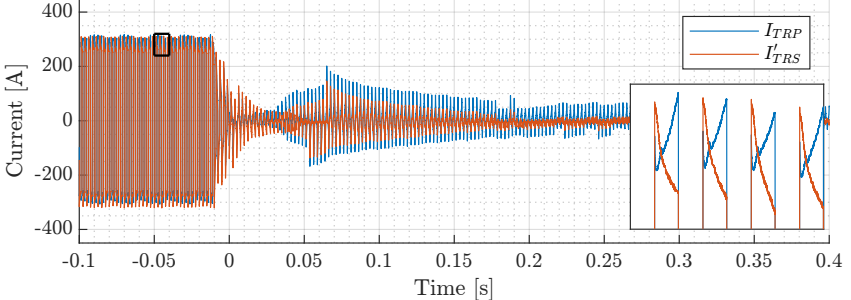

(c) SPS, $250 A \rightarrow 0 A$

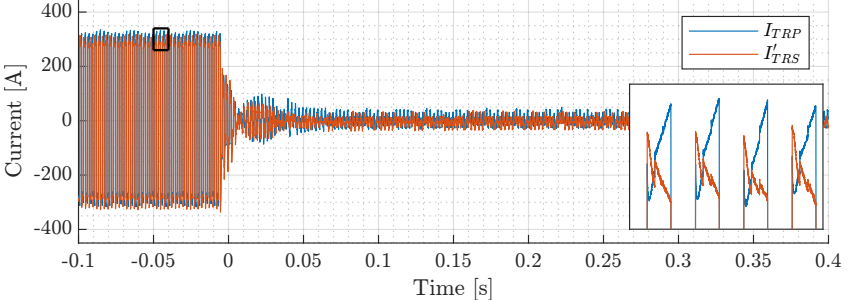

(d) CCP-SPS, $250 A \rightarrow 0 A$

Fig. 7. $360 \mathrm{~kW}$ DAB converter test results when fast load current change was applied (1ms).
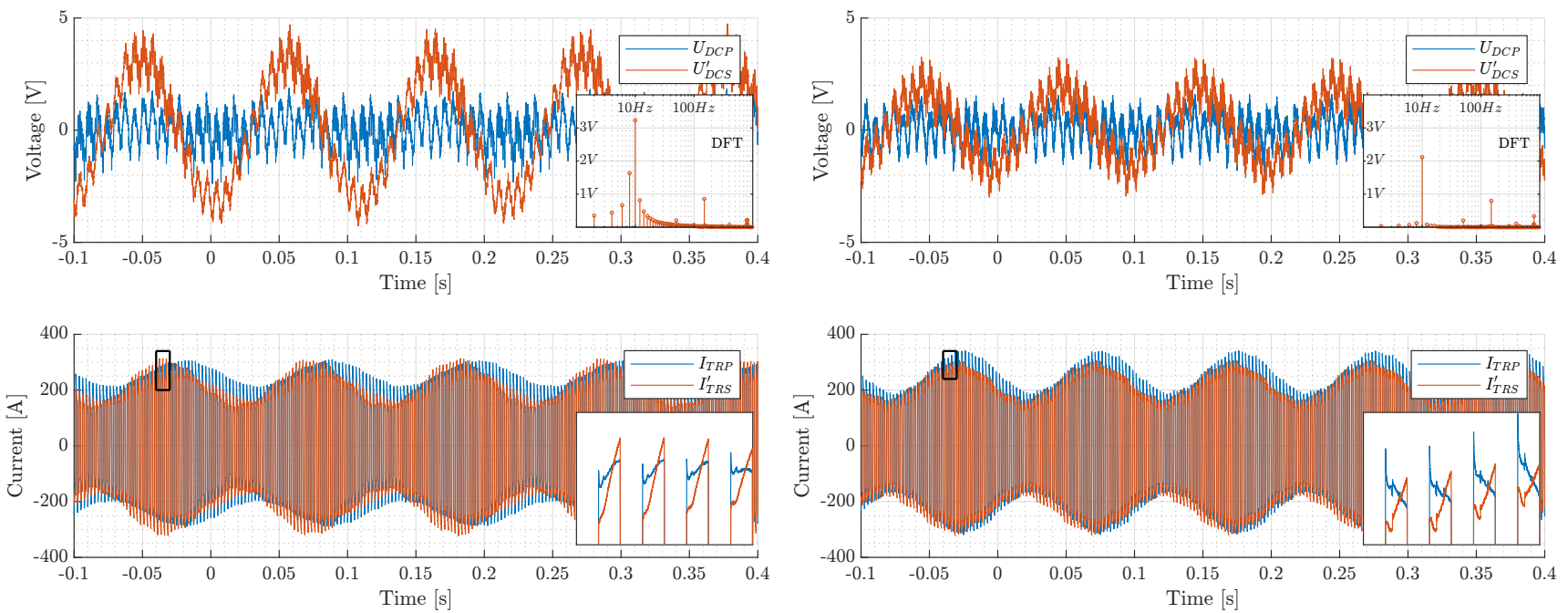

(a) SPS

(b) CCP-SPS

Fig. 8. $360 k W$ DAB converter test results when $250 A+50 A \sin (2 \pi 10 t)$ waveform was used as load current. The voltage was measured with AC coupling. 


\section{Acknowledgement}

The research reported in this paper and carried out at the Budapest University of Technology and Economics has been supported by the National Research Development and Innovation Fund based on the charter of bolster issued by the National Research Development and Innovation Office under the auspices of the Ministry for Innovation and Technology.

\section{References}

[1] R. W. A. A. DeDoncker, D. M. Divan and M. H. Kheraluwala (1991) "A three-phase soft-switched highpower-density DC/DC converter for high-power applications". IEEE Transactions on Industry Applications, vol. 27(1), pp. 63-73. ISSN 1939-9367.

[2] R. W. DeDoncker, M. H. Kheraluwala and D. M. Divan (1991). "Power Conversion Apparatus For DC/DC Conversion Using Dual Active Bridges".

[3] M. N. Kheraluwala, R. W. Gascoigne, D. M. Divan and E. D. Baumann (1992) "Performance characterization of a high-power dual active bridge DC-to-DC converter". IEEE Transactions on Industry Applications, vol. 28(6), pp. 1294-1301. ISSN 1939-9367.

[4] B. Zhao, Q. Yu and W. Sun (2012) "Extended-PhaseShift Control of Isolated Bidirectional DC-DC Converter for Power Distribution in Microgrid". IEEE Transactions on Power Electronics, vol. 27(11), pp. 4667-4680. ISSN 0885-8993.

[5] T. Hirose and H. Matsuo (2010) "A consideration of bidirectional superposed dual active bridge dc-dc converter". Proc. 2nd Int. Symp. Power Electronics for Distributed Generation Systems. ISSN 2329-5759, pp. $39-46$.

[6] F. Krismer and J. W. Kolar (2012) "Closed Form Solution for Minimum Conduction Loss Modulation of DAB Converters". IEEE Transactions on Power Electronics, vol. 27(1), pp. 174-188. ISSN 0885-8993.

[7] W. Han and L. Corradini (2018) "Control Technique for Wide-Range ZVS of Bidirectional Dual-bridge Series Resonant dc-dc Converters". IEEE 19th Workshop on Control and Modeling for Power Electronics (COMPEL).

[8] W. Han and L. Corradini (2019) "Wide-Range ZVS Control Technique for Bidirectional Dual-Bridge Series Resonant dc-dc Converters". IEEE Transactions on Power Electronics.

[9] T. Liu, X. Yang, W. Chen, Y. Li, Y. Xuan, L. Huang and X. Hao (2019) "Design and Implementation of High Efficiency Control Scheme of Dual Active Bridge Based $10 \mathrm{kV} / 1 \mathrm{MW}$ Solid State Transformer for PV Application". IEEE Transactions on Power Electronics, vol. 34(5), pp. 4223-4238. ISSN 0885-8993.

[10] H. Beiranvand, E. Rokrok and M. Liserre (2019) "Volume Optimization in Si IGBT based Dual-ActiveBridge Converters". 2019 10th International Power Electronics, Drive Systems and Technologies Conference (PEDSTC).

[11] S. Veréb, A. Futó, Z. Sütő, A. Balogh and I. Varjasi (2019) "Cross-Period Single Phase Shift Control Technique for High Power and Low Frequency Dual Active
Bridge Converters". 2019 International Conference on Electrical Drives \& Power Electronics (EDPE). IEEE. ISBN 978-1-7281-0390-7. ISSN 1339-3944, pp. 385390.

[12] S. Veréb, A. Futó, Z. Sütő, A. Balogh and I. Varjasi (2020) "Adaptive Dead Time Compensation for Cross-Period Single Phase Shift Control of Dual Active Bridge Converters". Renewable Energy \& Power Quality Journal (RE\&PQJ), vol. 18, pp. 327-332. ISSN 2172-038X. 